\title{
Experimental Study of Heat Transfer Enhancement in Tube in Tube Heat Exchanger using Rectangular Wing Type Vortex Generator
}

\author{
V.A. Chormale* and D.D. Palande \\ Department Mechanical Engineering, MCOERC, Nashik, Savitribai Phule Pune University, India
}

Accepted 15 June 2016, Available online 20 June 2016, Special Issue-5 (June 2016)

\begin{abstract}
Vortex generator is responsible for creating the turbulence in the flow of fluid. The experiment is carried out to enhance the heat transfer coefficient with installing the rectangular wing type of vortex generator in tube in tube heat exchanger, these vortex generators are provided on cross shape plate by lancing operation and this cross shape plate is inserted in the test section. These vortex generators cause stream wise longitudinal vortices in the test section which disrupt the growth of the thermal boundary layer and enhances heat transfer rate. Influence of geometrical parameter of rectangular wing vortex generator such as wing height, longitudinal wing pitch and wings attach angle on heat transfer coefficient is studied. Air is taken as the working fluid, the flow regime is assumed to be laminar. By varying the above parameter the heat transfer coefficient is calculated and by comparing all the result optimum size of rectangular wing is achieved.
\end{abstract}

Keywords: Vortex generator, Rectangular wing, Heat exchanger, Cross plate.

\section{Introduction}

The process of improving the performance of a heat transfer system is referred as the heat transfer enhancement technique. In order to enhance heat transfer and to improve the thermal performance of the heat exchangers augmentation techniques are widely used. These techniques are classified as Passive Techniques, Active Techniques and Compound Techniques. Passive Techniques are the techniques generally use surface or geometrical modifications to the flow channel by incorporating inserts or additional devices. Passive techniques promote higher heat transfer coefficient by disturbing or altering the existing flow behavior but they leads to an increase in fluid pressure drop. Some Passive heat transfer enhancement techniques are treated surfaces, rough surfaces, extended surfaces, inserts. Active heat transfer enhancement techniques involves some external power input for the enhancement of heat transfer, examples are mechanical aids, surface vibration, fluid vibration, electrostatic fields, suction and jet impingement. When any two or more techniques employed simultaneously to obtain enhancement in heat transfer that is greater than that produced by either of them when used individually, is termed as compound enhancement.

In this work Tubular or tube in tube heat exchanger is used with a rectangular wing type vortex generator.

*Corresponding author: V.A. Chormale
Tube in tube heat exchangers consist of two tubes, an inner and an outer coiled together. Heat transfer enhancement in tube in tube heat exchanger is possible by providing the vortex generator in inner tube. Types of vortex generator are rectangular wing, rectangular winglet, delta wing, delta winglet and trapezoidal wing. In this study rectangular wing type vortex generator are used. Geometrical parameter of rectangular wing having an influence on heat transfer coefficient and Nusselt number (Aliabadi, et al, 2015). The heat transfer coefficient and pressured drop values enhance as the wings height, longitudinal wings pitch, and transverse wings pitch decrease and the wings width, channel length, and wings attack angle increase. while the channel with the wings attach angle of $90^{\circ}$ presented the highest pressure drop values, the channel with the wings attach angle of $60^{\circ}$ showed a better heat transfer performance. In the study of Vortex-generator as core surface and nano fluid as working media (Aliabadi, et al, 2014).

The mixture model showed a better prediction of nano fluids flow inside the tested vortex-generator channel at the studied range. In the comparative study of the airside performance of fin and tube heat exchangers having plain, louver, and semi-dimple vortex generator (Wang, et al, 2015) For the airside performance for $\mathrm{N}=1$ with a smaller fin pitch of 1.6 $\mathrm{mm}$, the heat transfer coefficient for the louver fin geometry is higher than that of semi-dimple vortex generator and plain fin geometry. In the Experimental 
and thermodynamical analyses of the diesel exhaust vortex generator heat exchanger (Hatami, et al, 2015) vortex generator heat exchanger can enhance exergy recovery more than $50 \%$ compared to previous simple designs due to flow recirculation produced by vortex generator and destroy the boundary layer for a better mixed flow. In the numerical simulation on flow and heat transfer of fin and tube heat exchanger with longitudinal vortex generators (Li, et al, 2015) The rectangular winglet with angle of attack of $25^{\circ}$ showed the best overall performance than any other angles of attack in rectangular winglets configurations. In Heat transfer and fluid flow analysis in plate-fin and tube heat exchangers with a pair of block shape vortex generators (Leu, et al, 2004) case of span angle is equal to $45^{\circ}$ provides the best heat transfer augmentation. In the current work rectangular wing type vortex generator are used in tube in tube heat exchanger and the influence of geometrical parameter of rectangular wing such as wing height, longitudinal wing pitch and wing attach angle on heat transfer coefficient was studied.

\section{Experimentation}

To study the heat transfer enhancement in tube in tube heat exchanger using rectangular wing type vortex generator the experimental facility used is a simple forced convection setup. The test section or tube is fitted with the blower for forced convection environment.

\subsection{Experimental Setup}

The experimental setup consists of following main components

1. Blower: Blower is used to circulate the air in the experimental setup.

2. Test Section: The test section is length of tube in which cross shape plate is to be placed and is heated from outside. The test section length selected is 600 $\mathrm{mm}$, inner Diameter is $54 \mathrm{~mm}$ and outer Diameter is $56 \mathrm{~mm}$

3. Calming Tube: The Calming tube section is provided to allow the flow to be hydro-dynamically fully developed. Length of Calming tube is $2000 \mathrm{~mm}$

4. Venturimeter: It is used to measure the mass flow rate, and thereby velocity of air. The venturimeter is fitted across the delivery side of the pump to avoid the effect of its back pressure on test section. The volumetric flow rates from the blower were adjusted by flow control valve fitted at delivery end.

5. Manometer: U-tube manometer is used to measure the pressure drop across the test section. The range of the manometer is $0-300 \mathrm{~mm}$ of water column.

6. Heater: Uniform heat flux is applied to the test tube by heating it with band heater. The mechanism of heat production is based on principle of electrical resistance heating. The electrical output power can be controlled by a dimmer stat to provide constant heat flux along the entire length of the test section. The capacity of heater is 300 watt, $230 \mathrm{~V} \mathrm{AC}$ supply is to be provided.

7. Thermocouples and Control Panel: The surface temperature of the tube wall is measured by $\mathrm{K}$ type thermocouples, which are placed on the surface of the tube. Eight thermocouples are placed on the surface of the test section to measure the surface temperature and two thermocouples are placed at the inlet and outlet of the test section to measure the inlet and outlet temperature of the water. To measure the outer surface temperature of insulation two thermocouples are mounted at outer surface of insulation. The range of thermocouple is $0-200^{\circ} \mathrm{C}$.

Control Panel consist of dimmer stat, temperature indicator and on-off switch.

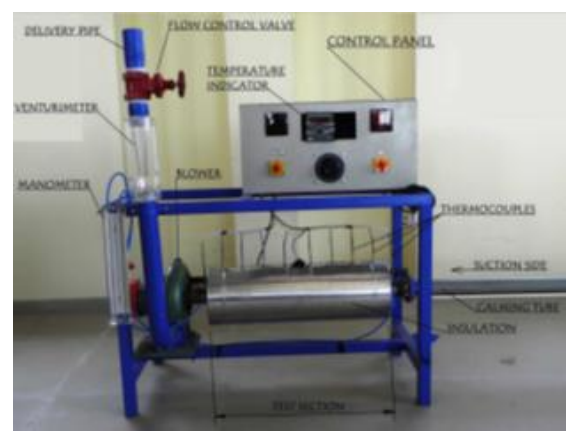

Fig 1. Experimental setup

\subsection{Design of Cross plate}

The length of the cross plate $600 \mathrm{~mm}$. vortex generators are provided on cross shape plate by lancing operation and this cross shape plate is inserted in the test section. Numbers of cross plates are designed by varying the different geometrical parameter such as wing height, longitudinal wings pitch and wings attach angle.

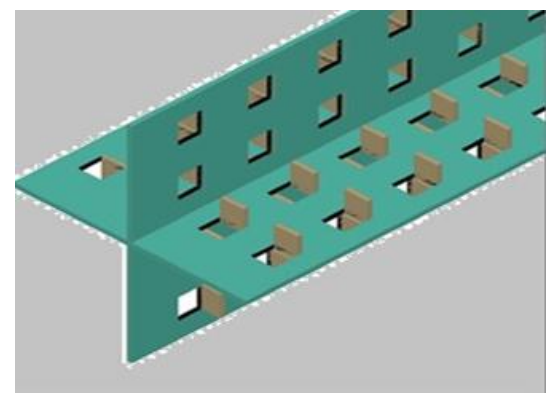

Fig 2. 3D view of Cross shape plate

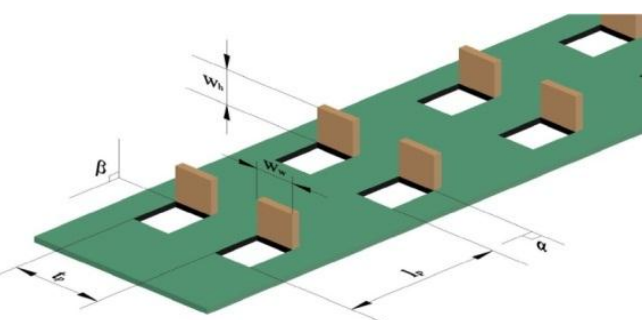

Fig 3. Cross plate with geometrical parameter 
In Design of cross shape plate following geometrical parameter are taking in consideration;

$\mathrm{W}_{\mathrm{h}}$ : Wing height $\quad \mathrm{W}_{\mathrm{w}}$ : Wing width

$l_{p}$ : Longitudinal wings pitch $t_{p}$ :Transverse wings pitch $\alpha$ : Wings attack angle $\quad \beta$ : Wings attach angle

Geometrical parameters for studied models are as follows

Table 1 Geometrical parameters

\begin{tabular}{|c|c|c|}
\hline Parameter & Symbol & Value \\
\hline Wing height & $\mathrm{W}_{\mathrm{h}}(\mathrm{mm})$ & $5.0,7.5$ \\
\hline Wing width & $\mathrm{W}_{\mathrm{w}}(\mathrm{mm})$ & 5.0 \\
\hline Longitudinal wings pitch & $\mathrm{l}_{\mathrm{p}}(\mathrm{mm})$ & $10,12.5$ \\
\hline Transverse wings pitch & $\mathrm{t}_{\mathrm{p}}(\mathrm{mm})$ & 7.0 \\
\hline Wings attach angle & $\beta\left(^{\circ}\right)$ & 45,90 \\
\hline Wings attack angle & $\alpha\left(^{\circ}\right)$ & 90 \\
\hline
\end{tabular}
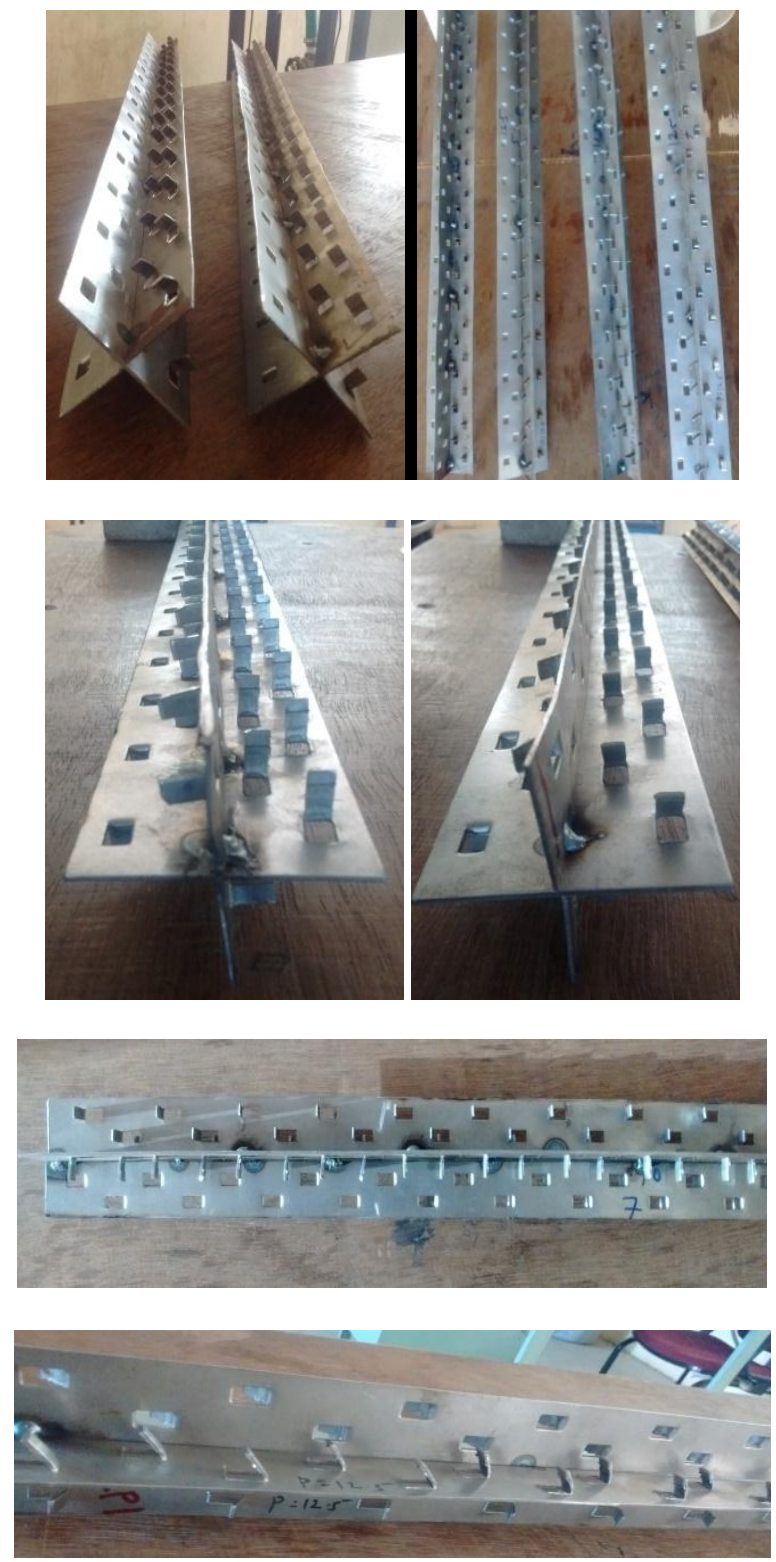

Fig 4. Cross plates
Following table shows the cross plate with different configuration for the experimental analysis

Table 2 Cross plate with different configuration

\begin{tabular}{|c|c|c|c|c|c|c|}
\hline $\begin{array}{c}\text { Cross } \\
\text { Plate }\end{array}$ & $\begin{array}{c}\mathrm{W}_{\mathrm{h}} \\
(\mathrm{mm})\end{array}$ & $\begin{array}{c}\mathrm{W}_{\mathrm{w}} \\
(\mathrm{mm})\end{array}$ & $\begin{array}{c}\mathrm{l}_{\mathrm{p}} \\
(\mathrm{mm})\end{array}$ & $\begin{array}{c}\mathrm{t}_{\mathrm{p}} \\
(\mathrm{mm})\end{array}$ & $\begin{array}{c}\beta \\
\left.{ }^{\circ}\right)\end{array}$ & $\begin{array}{c}\alpha \\
\left({ }^{\circ}\right)\end{array}$ \\
\hline CP01 & 7.5 & 5.0 & 12.5 & 7.0 & 45 & 90 \\
\hline CP02 & 7.5 & 5.0 & 12.5 & 7.0 & 90 & 90 \\
\hline CP03 & 7.5 & 5.0 & 10.0 & 7.0 & 45 & 90 \\
\hline CP04 & 7.5 & 5.0 & 10.0 & 7.0 & 90 & 90 \\
\hline CP05 & 5.0 & 5.0 & 12.5 & 7.0 & 45 & 90 \\
\hline CP06 & 5.0 & 5.0 & 12.5 & 7.0 & 90 & 90 \\
\hline CP07 & 5.0 & 5.0 & 10.0 & 7.0 & 45 & 90 \\
\hline CP08 & 5.0 & 5.0 & 10.0 & 7.0 & 90 & 90 \\
\hline
\end{tabular}

\section{Result and Discussion}

\subsection{Validation of experimental facility}

To check the accuracy and correctness of the given experimental facility here the comparison made between the smooth tube result and result obtained from the previous correlations. To validate the experimental setup correlations used are Gnielinski correlation for Nusselt number and Petukhov Correlation For friction factor.

Gnielinski correlation for Nusselt number is given as,

$$
N u=\frac{(f \div 8)(\operatorname{Re}-1000) \operatorname{Pr}}{1+12.7(f \div 8)^{0.5}\left(\operatorname{Pr}^{2 / 3}-1\right)}
$$

Petukhov Correlation For friction factor is given as, $f=(0.790 \ln \operatorname{Re}-1.64)^{-2}$

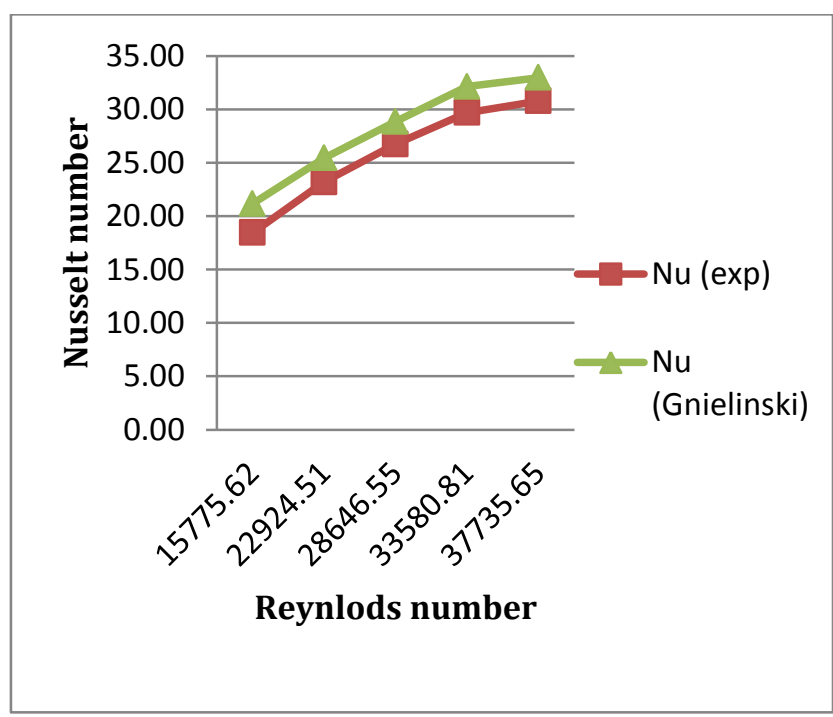

(a) 


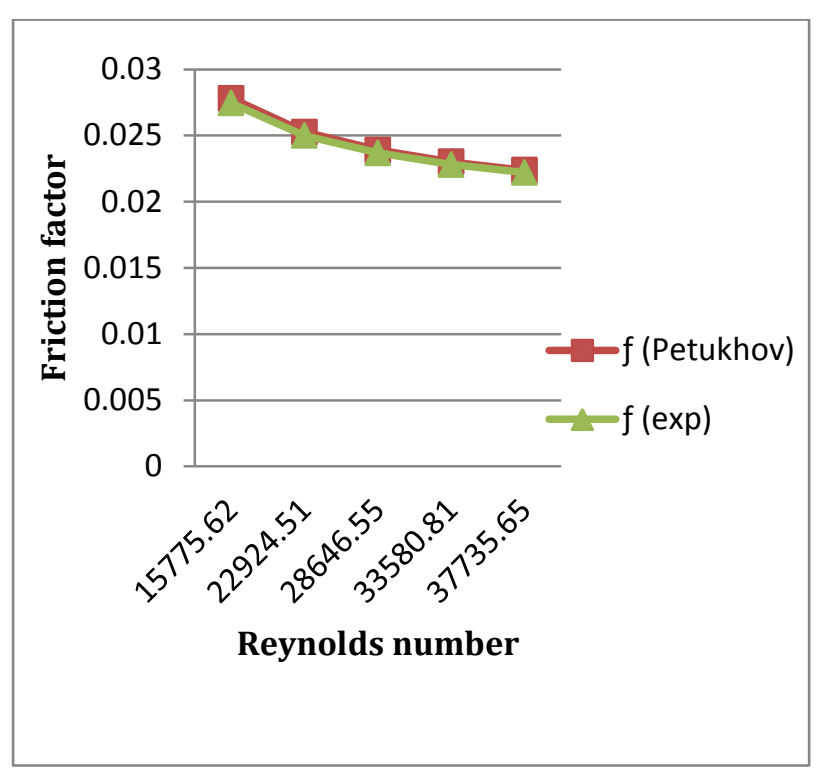

(b)

Fig 5. (a) Nusselt number-Reynolds number (b) friction factor-Reynolds number for the smooth tube

The Nusselt number and friction factor are plotted against Reynolds number for the values obtained from experimental data and that from Gnielinski correlation and Petukhov Correlation. The good agreement between Nusselt number and friction factor obtained from experimental data and correlation shows that the experimental facility is reliable.

\subsection{Result for different configuration of Cross plate}

Experiment is performed by inserting the different configuration of Cross shaped plate in the test section and results are obtained.

\subsubsection{Result for $\mathrm{Wh}=7.5 \mathrm{~mm}$}

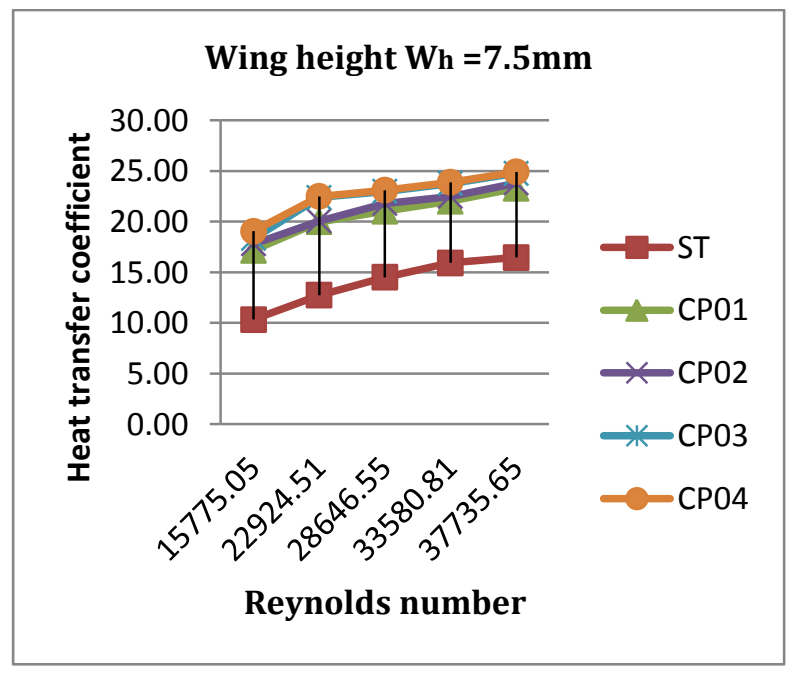

Fig 6. Variation of Heat transfer coefficient with Reynolds number for different longitudinal pitch and wing attach angle

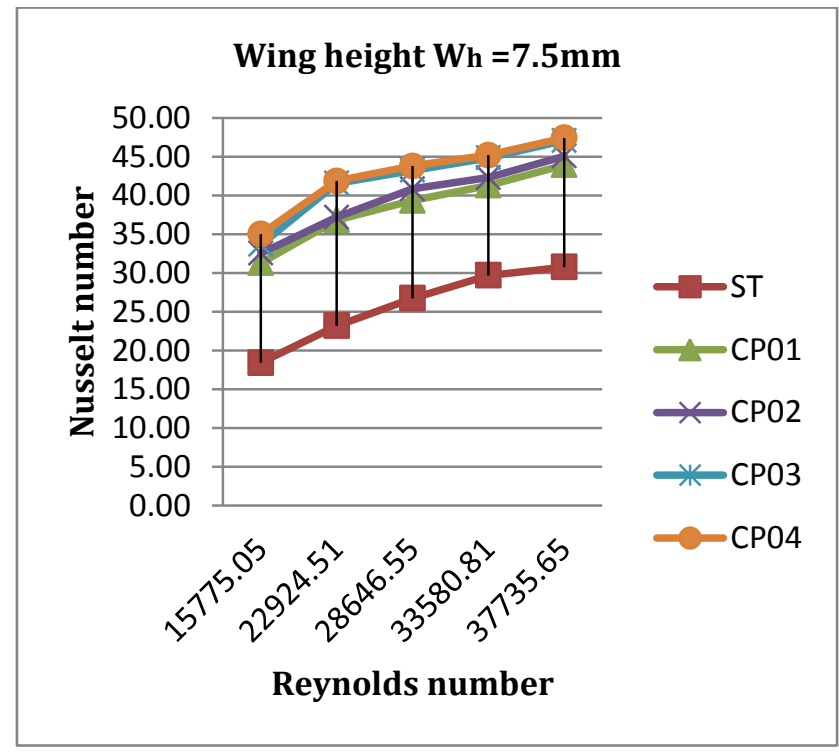

Fig 7. Variation Nusselt number with Reynolds number for different longitudinal pitch and wing attach angle

Experimental values of heat transfer coefficient and Nusselt number for wing height $7.5 \mathrm{~mm}$ against the Reynolds number of air flow inside the test section with different longitudinal wing pitch and different wing attach angle are presented.

The result show that higher value of heat transfer coefficient for the longitudinal wing pitch $10 \mathrm{~mm}$ and Wing attach angle $90^{\circ}$. By inserting CP01 the heat transfer coefficient is increase by $49.55 \%$. For wing height $7.5 \mathrm{~mm}$ higher percentage of increase of heat transfer coefficient is $64.37 \%$ which is obtained from CP04. Also the higher value of Nusselt number is obtained for CP04. and the percentage increase of Nusselt number is $68.14 \%$.

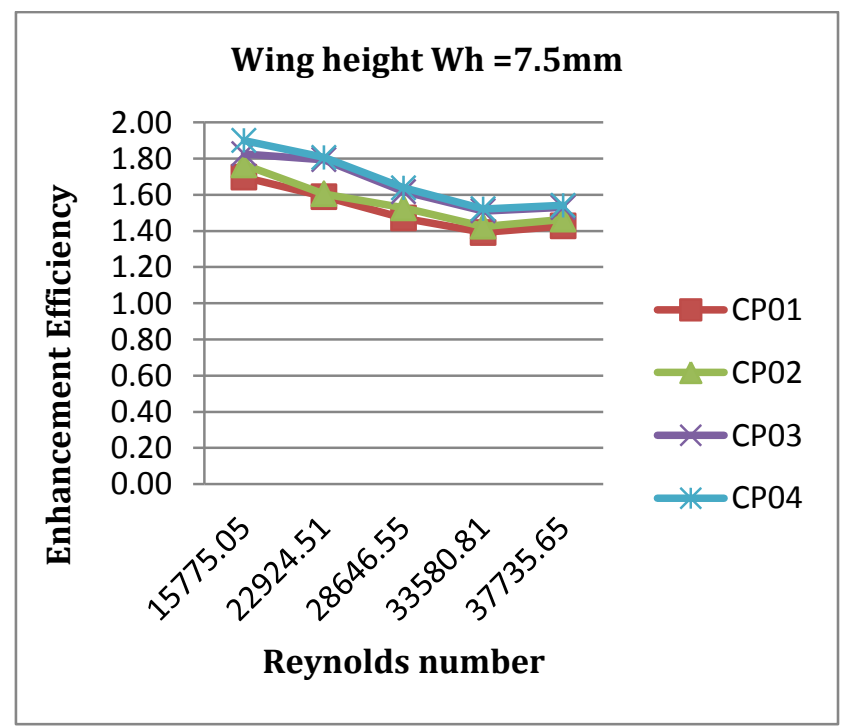

Fig 8. Variation of Enhancement efficiency with Reynolds Number for different longitudinal pitch and wing attach angle 
Amongst the configuration tested for wing height $7.5 \mathrm{~mm}$ CP04 gives the best enhancement efficiency of 1.9 at Reynolds number 15775.

\subsubsection{Result for $\mathrm{Wh}=5.0 \mathrm{~mm}$}

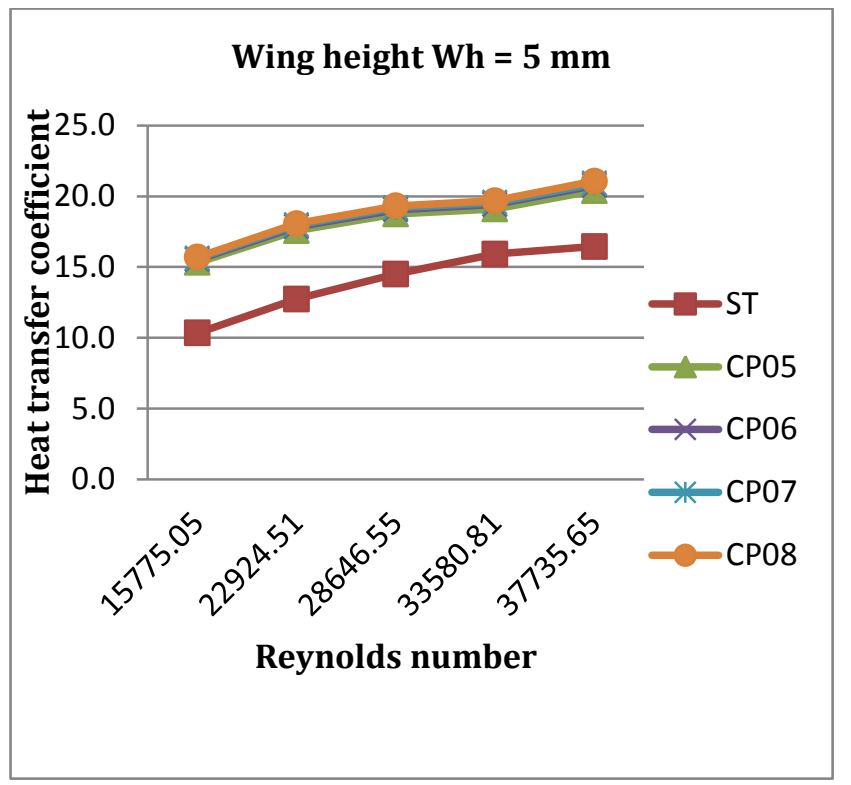

Fig 9. Variation of Heat transfer coefficient with Reynolds number for different longitudinal pitch and wing attach angle

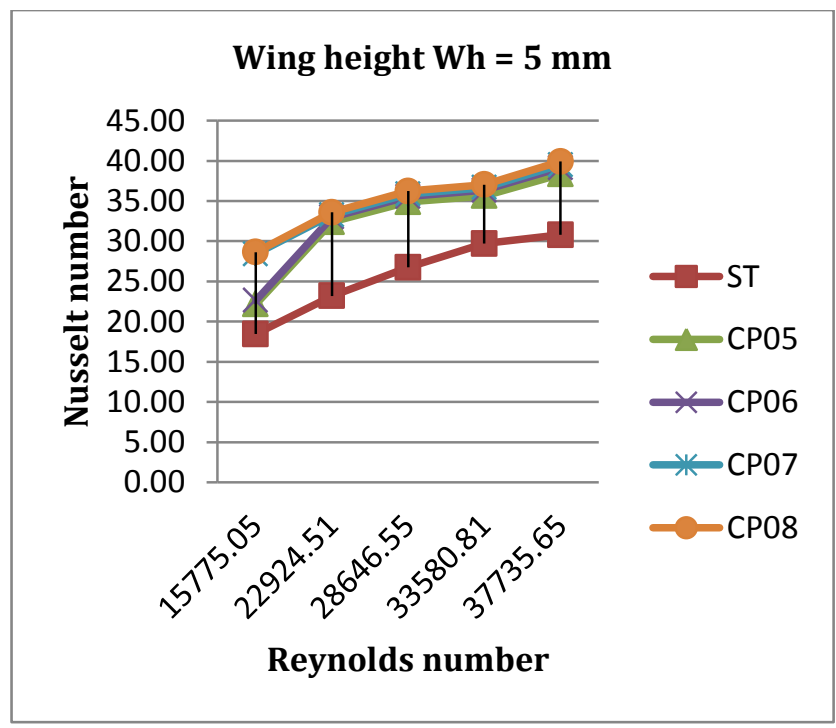

Fig 10. Variation Nusselt number with Reynolds number for different longitudinal pitch and wing attach angle

Experimental values of heat transfer coefficient and Nusselt number for wing height $5.0 \mathrm{~mm}$ against the Reynolds number of air flow inside the test section with different longitudinal wing pitch and different wing attach angle are presented.

The result show that higher value of heat transfer coefficient for the longitudinal wing pitch $10 \mathrm{~mm}$ and Wing attach angle $90^{\circ}$. By inserting CP05 the heat transfer coefficient is increase by $31.83 \%$. For wing height $5.0 \mathrm{~mm}$ higher percentage of increase of heat transfer coefficient is $35.73 \%$ which is obtained from CP08. Also the higher value of Nusselt number is obtained for CP08 and the percentage increase of Nusselt number is $37.95 \%$.

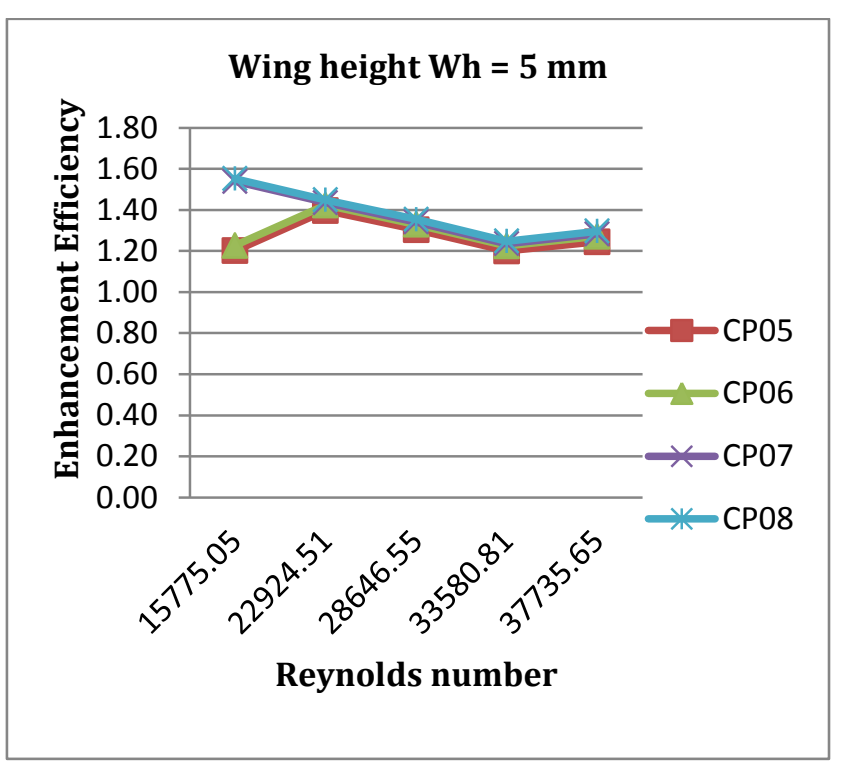

Fig 11. Variation of Enhancement efficiency with Reynolds Number for different longitudinal pitch and wing attach angle

Amongst the configuration tested for wing height $5.0 \mathrm{~mm}$ CP08 gives the best enhancement efficiency of 1.55 at Reynolds number 15775.

\section{Conclusion}

Tube in tube heat exchanger with rectangular wing type vortex generator on cross plate having better heat transfer coefficient than with smooth tube

The value heat transfer coefficient enhance as the longitudinal wing pitch decreases

As the wing attach angle increases the heat transfer coefficient also increases

The value heat transfer coefficient increases with the increase in wing height.

\section{References}

M. Khoshvaght Aliabadi, S. Zangouei, F. Hormozi, (2015), Performance of a plate-fin heat exchanger with vortexgenerator channels: 3D-CFD simulation and experimental validation, International Journal of Thermal Sciences, vol.88, pp. 180-192.

M. Khoshvaght Aliabadi, F. Hormozi ,A. Zamzamian, (2014), Effects of geometrical parameters on performance of platefin heat exchanger: Vortex-generator as core surface and nanofluid as working media, Applied Thermal Engineerin, vol.70, pp. 565-579.

Chi-Chuan Wang, Kuan-Yu Chen, Jane-SunnLiaw, Chih-Yung Tseng, (2015), An experimental study of the air-side performance of fin-and-tube heat exchangers having plain, louver, and semi-dimple vortex generator configuration, 
International Journal of Heat and Mass Transfer, vol.80, pp. 281-287.

M. Hatami, D.D. Ganji, M. Gorji-Bandpy, (2015) ,Experimental and thermodynamical analyses of the diesel exhaust vortex generator heat exchanger for optimizing its operating condition, Applied Thermal Engineering, vol.75, pp. 580591.

M. Hatami, D.D. Ganji, M. Gorji-Bandpy, (2015), Experimental investigations of diesel exhaust exergy recovery using delta winglet vortex generator heat exchanger, International Journal of Thermal Sciences, vol.93, pp. 52-63.

A.A. Gholami, Mazlan A.Wahid, H.A. Mohammed, (2014), Heat transfer enhancement and pressure drop for fin-and-tube compact heat exchangers with wavy rectangular winglettype vortex generators, International Communications in Heat and Mass Transfer, vol.54, pp. 132-140.

H.H. Xia, G.H. Tang, Y. Shi, W.Q. Tao, (2014), Simulation of heat transfer enhancement by longitudinal vortex generators in dimple heat exchangers, Energy, vol.74, pp.27e36.

Jin-Sheng Leu, Ying-Hao Wu, Jiin-Yuh Jang, (2004), Heat transfer and fluid flow analysis in plate-fin and tube heat exchangers with a pair of block shape vortex generators, International Journal of Heat and Mass Transfer, vol.47, pp. 4327-4338.
Hung-Yi Li, Ci-Lei Chen, Shung-Ming Chao, Gu-Fan Liang, (2013), Enhancing heat transfer in a plate-fin heat sink using delta winglet vortex generators, International Journal of Heat and Mass Transfer, vol.67, pp. 666-677.

Pankaj Saha, Gautam Biswas, Subrata Sarkar,(2014), Comparison of winglet-type vortex generators periodically deployed in a plate-fin heat exchanger - A synergy based analysis, International Journal of Heat and Mass Transfer vol.74, pp. 292-305.

Leandro O. Salviano, Daniel J. Dezan, Jurandir I. Yanagihara, (2015), Optimization of winglet-type vortex generator positions and angles in plate-fin compact heat exchanger: Response Surface Methodology and Direct Optimization, International Journal of Heat and Mass Transfer, vol.82, pp. 373-387.

Babak Lotfi, Bengt Sunden, Qiuwang Wang, (2015), An investigation of the thermo-hydraulic performance of the smooth wavy fin-and-elliptical tube heat exchangers utilizing new type vortex generators, Applied Energy, vol.75, pp. 352-262.

Li Li, Xiaoze Du, Yuwen Zhang, Lijun Yang, Yongping Yang, (2015), Numerical simulation on flow and heat transfer of fin-and-tube heat exchanger with longitudinal vortex generators, International Journal of Thermal Sciences, vol.92, pp. 85-96. 